\title{
A Review on Metals Induced Oxidative Stress in Fish
}

\author{
Babita Rani ${ }^{1}$ and Renu Singh ${ }^{2 *}$ \\ ${ }^{1}$ Department of Biochemistry, ${ }^{2}$ Department of Biotechnology, CCS HAU, \\ Hisar, Haryana, India \\ *Corresponding author
}

\section{Keywords}

Reactive oxygen

species,

Glutathione,

Superoxide

dismutase

Antioxidant system,

Free radical

\section{Article Info}

Accepted:

04 June 2019

Available Online:

10 July 2019

\section{A B S T R A C T}

Oxidative stress results from an imbalance between the production of reactive oxygen species and the antioxidants defences, in favour of the former. In recent years, the association between oxidative processes, environmental change and life histories has received much attention. Metals are important inducers of oxidative stress in aquatic organisms, promoting formation of reactive oxygen species through two mechanisms. Redox active metals generate reactive oxygen species through redox cycling, while metals without redox potential impair antioxidant defences, especially that of thiol-containing antioxidants and enzymes. Elevated levels of reactive oxygen species lead to oxidative damage including lipid peroxidation, protein and DNA oxidation, and enzyme inactivation. Antioxidant defences include the enzyme system and low molecular weight antioxidants. Metal-binding proteins, such as ferritin, ceruloplasmin and metallothioneins, have special functions in the detoxification of toxic metals and also play a role in the metabolism and homeostasis of essential metals. Antioxidative compounds are found in all fish species to protect their lipids and other compounds that contain double bonds, against damage caused by reactive oxygen species.

\section{Introduction}

Molecular oxygen is a necessary compound for all aerobic organisms, since this element is critical for energy production; however, is a potent oxidant, which can lead to oxidative stress. The reactive oxygen species (ROS) produced and the resulting free radicals are results of normal cell metabolism, and many of these compounds play a key role in various metabolic pathways. Many of these components are essential in the organism defense and their byproducts are considered potent bactericides that act actively in the destruction of invasive pathogens (Cross et al., 1987; Dong et al., 2017; Biller-Takahashi et al., 2015). Oxidative stress occurs when there is an imbalance between the production of oxidant and antioxidant components. The organism during its normal metabolism produces several ROSs, however, it has an antioxidant defense system that keeps the 
levels of these oxidizing compounds at an acceptable level. In some situations the oxidants production is very high and the cells can suffer serious damage and die (Dong et al., 2017; Finkel, 2011; Kiley and Storz, 2004; Li et al., 2016). Antioxidant enzymes and important indicators of oxidative stress. Reduced glutathione (GSH) and oxidized glutathione disulphide (GSSG) play a key role in non-enzymatic antioxidant defence. Metalbinding proteins such as ferritin, ceruloplasmin, and metallothioneins (MTs) have special functions in the detoxification of toxic metals, and also play a role in the metabolism and homeostasis of essential metals (Kelly et al., 1998). Studies of the fish free radicals production are preliminary, but there are two factors that positively influence the oxidative stress studies in this species; one of them is that fish are considered biological indicators of pollution, which is a factor that promotes the generation of free radicals by the aquatic organism. Second is that many fish are considered biological models for metabolic pathways evaluation, so, due to the importance of the theme, other studies should be carried out to evaluate the ROS effects on fish, including their beneficial effect against pathogens and deleterious impact on the oxidation of cellular components (Ahmad et al., 2000).

Metals, especially heavy metals, are important contaminants of aquatic environments worldwide. Metal pollution has increased with the technological progress of human society. Industry, mining, advanced agriculture, household waste, and motor traffic is all among the activities considered to be major sources of metal pollution. Metals can accumulate in aquatic organisms, including fish, and persist in water and sediments (Luoma and Rainbow, 2008a). Metals are well-known inducers of oxidative stress, and assessment of oxidative dam-age and antioxidant defences in fish can reflect metal contamination of the aquatic environment (Livingstone, 2003). Speciation of metals, their solubility and complexation, are important factors that influence the toxicity of metals in the aquatic environment. The amount of dissolved metal strongly depends on water $\mathrm{pH}$. The interaction of metals can alter their toxic effects on aquatic organisms both positively and negatively (Jezierska and Witeska, 2001). Different modes of exposure to metals also play a role in metal toxicity. Fish take up metals through the gills, digestive tract and body surface (Tao et al., 2001; Kamunde et al., 2002). Various metal ions are involved in oxidative stress in fish.

\section{Oxidative Stress}

Oxidative stress is a condition that refers to the imbalance between levels of reactive oxygen species (ROS) and their antioxidants. Reactive oxygen species may be increased and damage lipids, proteins and DNA. Oxidative stress has been linked to a wide variety of diseases; however, ROS molecules also act on immune defense, as well as signaling molecules and on the maintenance of physiological processes (Figure 1) (Wood et al., 2003; Schieber and Chandel, 2014). They may also be classified as free radicals, since chemical properties give them reactivity to different biological targets, and when in excess they can cause peroxidation of membrane lipids, impairment of proteins in tissues, membranes, enzymes, carbohydrates and DNA. Free radicals are highly reactive atoms or molecules that have an unpaired electron in their last electron layer.

Reactive oxygen species are produced mainly in the mitochondria, peroxisomes, cytoplasm and plasma membrane. Oxygen is a biradical that has two radicals in the orbitals, which makes it little reactive, however, the electron transfer or energy absorption processes can promote the ROS formation from molecular 
oxygen. ROS include oxygen free radical (FR), such as the hydroxyl radical $\left(\mathrm{HO}^{\circ}\right)$, superoxide anion $\left(\mathrm{O}_{2}{ }^{\circ}\right)$, peroxyl $\left(\mathrm{ROO}^{\circ}\right)$ and alkoxyl ( $\left.\mathrm{RO}^{\circ}\right)$, nitric oxide (NO), but also nonradical compounds, such as oxygen, hydrogen peroxide $\left(\mathrm{H}_{2} \mathrm{O}_{2}\right)$, hypochlorous acid $(\mathrm{HClO})$, and transition metals ( $\mathrm{Cu}$ and $\mathrm{Fe}$ ) (Sorg, 2004; Barreiros et al., 2006). The FR have a different degree of reactivity and half-life, but most of them are very unstable and can promote the non-enzymatic oxidation of biomolecules (proteins, carbohydrates, lipids and nucleic acids) (Halliwell, 2009; Buonocore et al., 2010; Hamanaka and Chandel, 2010).

Among the ROS, the hydroxyl radical $\left(\mathrm{HO}^{\circ}\right)$ is the most harmful, because there is great difficulty in its sequestration out of the cells due to its very short half-life. This free radical is formed in the body by reaction of $\mathrm{H}_{2} \mathrm{O}_{2}$ with transition metals and by homolysis of water by exposure to ionizing radiation. There is no antioxidant capable of preventing the $\mathrm{HO}^{\circ}$ action, it is only possible to inhibit its formation or repair the damage caused by it (Halliwell et al., 1992; Barreiros et al., 2006). The superoxide anion radical $\left(\mathrm{O}_{2}{ }^{--}\right)$is usually inactive, and in aqueous media produces a hydrogen peroxide molecule and an oxygen molecule by dismutation. This free radical is part of several chemical reactions with important biological functions, such as $\mathrm{HO}^{\circ}$ radical production, by reducing Fe chelates, as well as $\mathrm{Fe}^{2+}$ released from storage proteins (ferritin and aconitase) and iron-sulfoproteins, in addition to reacting with the $\mathrm{HO}^{\circ}$ radical producing singlet oxygen $\left({ }^{1} \mathrm{O}_{2}\right)$ and reacting with nitric oxide (NO) producing peroxynitrite $\left(\mathrm{ONOO}^{-}\right)$(Babior, 1997; Halliwell, 2000; Barreiros et al., 2006). The superoxide radical, in spite of its deleterious effects, has important function for immune defense, because in phagocytic cells, lymphocytes and fibroblasts, the $\mathrm{O}_{2}{ }^{-}$has the capacity to destroy pathogens.
Hydrogen peroxide is a poorly reactive nonradical compound that can easily diffuse through cell membranes, and consequently promote the formation of the $\mathrm{HO}^{\circ}$ radical after binding with transition metals, which are usually present within the cell. This FR is generated by the dismutation of the superoxide anion by oxidases enzymes, or even through the oxidation of fatty acids. Hydrogen peroxide in the mitochondrial matrix is produced in abundance during the $\mathrm{O}_{2}$ reduction process but can be partially eliminated by the catalase, glutathione peroxidase enzymes and peroxidases bound to thioredoxin, or it may be further released into the cell cytoplasm. In phagocytes, $\mathrm{H}_{2} \mathrm{O}_{2}$ is a precursor of hypoalogens acids that are strong oxidants against pathogens, but also acts deleteriously on molecules of the organism itself (Husain et al., 1987; Halliwell, 2000).

\section{Antioxidant Defense System}

Oxidative stress is an unavoidable aspect of aerobic life. It is the result of an imbalance between the production of reactive oxygen species (ROS) and antioxidant defences in living organisms (Nishida, 2011). Elevated production of ROS can cause oxidation of proteins and lipids, alterations in gene expression, and changes in cell redox status (Livingstone, 2003). Mechanisms of antioxidant defences in fish include the enzyme system and low molecular weight antioxidants, similar to those in mammals, although the specific isoforms of enzymes in various fish species have not been well identified (Di Giulio and Meyer, 2008). The organism, in the face of the imbalance of free radical production, presents a strategy to inhibit its formation or to promote chemical reactions to reduce the high reactivity of these compounds through antioxidant components, such as enzymes or cofactors, obtained by the cell itself (endogenous source) or through diet (exogenous source). Antioxidants are 
substances that significantly delay or prevent the oxidation of an oxidizable substrate (Franco and Martínez-Pinilla, 2017; Sorg, 2004; Wang et al., 2013). Many studies have been conducted on fish to evaluate their antioxidant compounds to determine a database for comparative studies on the effects of natural environment, diet, seasonal variation, xenobiotics and others (Mattos et al., 2017; Moura et al., 2017; Winston, 1991; Halliwell et al., 1995; Pietta, 2000; Li et al., 2016). The antioxidants produced by the body act enzymatically by decreasing the excess of FR, through enzymatic components, such as the superoxide dismutase (SOD), catalase (CAT) and glutathione peroxidase (GPx) enzymes and through non-enzymatic components such as glutathione (GSH), histidine peptides, iron-bound proteins (transferrin and ferritin), dihydrolipoic acid and ubiquinone $\left(\mathrm{CoQH}_{2}\right)$. And some dietary antioxidants such as $\alpha$-tocopherol (vitamin-E), $\beta$-carotene (pro-vitamin-A), ascorbic acid (vitamin $\mathrm{C}$ ), micronutrients (selenium) and phenolic compounds, such as flavonoids and polyflavonoids (Albuquerque et al., 2017, 1995; Pietta, 2000). Fish present a complex antioxidant defense system that comprises several enzymes, among them SOD is widely found in the cytosol $\left(\mathrm{Cu}^{2+}-\mathrm{SOD}\right.$ and $\mathrm{Zn}^{2+}$ $\mathrm{SOD})$ and in the mitochondria $\left(\mathrm{Mn}^{2+}-\mathrm{SOD}\right)$, that acts on the superoxide anion transforming in $\mathrm{H}_{2} \mathrm{O}_{2}$, avoiding the accumulation of $\mathrm{O}_{2}{ }^{-}$, which is highly reactive and deleterious to the cell. The produced $\mathrm{H}_{2} \mathrm{O}_{2}$ can be eliminated by catalases, GPx and peroxidases bound to thioredoxin, or it may be further released into the cytoplasm of cells (Lambeth, 2004; Brand, 2010; Schieber and Chandel, 2014; Li et al., 2016). CAT (derived from mitochondria and peroxisomes) catalyzes the decomposition of $\mathrm{H}_{2} \mathrm{O}_{2}$ into $\mathrm{H}_{2} \mathrm{O}$ and $\mathrm{O}_{2}$, which is produced in abundance by phagocytes, and maintains the ideal balance of ROS formation and elimination, essential for the functioning of the innate defense system. Modulation of CAT production is important for many processes, such as proliferation, differentiation, cell migration and apoptosis (Underhill and Ozinsky, 2002; Oost et al., 2003, Malhotra and Kaufman, 2007; Veal et al., 2007; Zamocky et al., 2008, Wang et al., 2013). Hydrogen peroxide can also be neutralized by cytosolic or mitochondrial GPx in the presence of GSH. GSH also contributes to the removal of electrophilic components through the reaction with glutathione-S-transferase. The antioxidant system based on GSH acts in the presence of selenium, which is a very important micronutrient and widely studied in fish. GPx plays an important role in the prevention of lipid peroxidation, since it removes $\mathrm{H}_{2} \mathrm{O}_{2}$, consequently protects the membranes from peroxidation damage (Sies, 1986; Gaté et al., 1999; Oost, et al., 2003; Scandalios, 2005; Monteiro, et al., 2006). Antioxidants from diet are important to avoid the ROS effects (Lambeth, 2004; Brand, 2010). Ascorbic acid or vitamin C normally appears in the body as ascorbate form and is an excellent antioxidant in vivo, as it can be oxidized by most of the FR in aqueous solution, and converted into poorly reactive substances. Vitamin $\mathrm{C}$ acts by binding to ROS present in the body and restoring the FR through $\mathrm{H}^{+}$donation, in cell membranes it acts together with vitamin $\mathrm{E}$, regenerating the Vit $\mathrm{E}$ after ROS interaction. Vitamin $\mathrm{C}$ also acts as a reductor agent, mainly decreasing transition metals such as $\mathrm{Fe}$ and $\mathrm{Cu}$ ions that react with $\mathrm{H}_{2} \mathrm{O}_{2}$ to form the hydroxyl radical (Buettner, 1993; Babior, 1997). Vitamin E, in vivo, is a potent inhibitor of lipid peroxidation. It acts as an $\mathrm{H}^{+}$donor for the peroxyl radical, interrupting the FR formation chain reaction. The $\mathrm{H}^{+}$donation leads vitamin $\mathrm{E}$ loss of function, however, it can be regenerated with vitamin $\mathrm{C}$. The impact of the vitamin $\mathrm{E}$ on fish immune system have been extensively studied (Storey, 1996; Theriault et al., 1999; Monteiro et al., 2006). Selenium (Se), an essential micronutrient, is an integral part of several 
selenium-enzymes, among them GPx, iodothyronine deiodinase, thioredoxin reductase and selenophosphate synthetase. Selenium-enzymes is included on antioxidant defense system compound, as well as on metabolism of thyroid hormones, spermatogenesis and other biological processes, and it has been the subject of many studies on fish immune system. Some studies have demonstrated an improvement of humoral and cell-mediated immune responses following the selenium incorporation into the diet of fish (Hsu and Guo, 2002; BillerTakahashi et al., 2015; Chien et al., 2003).

Enzymatic and non-enzymatic antioxidants are essential to maintain the balance between production and elimination of FR from fish cells. Antioxidants are an important biological defense against OS involved in cell detoxification, and are very important for understanding the deleterious effects of FR (Bainy, 1996; Doyotte et al., 1997; Ahmad et al., 2000).

\section{Mechanisms of metal-induced oxidative damage}

The involvement of metals in oxidative damage is multi-faceted. In general, metals produce free radicals in two ways. Redox active metals such as iron, copper, chromium, and vanadium generate ROS through redox cycling. Metals without redox potential, such as mercury, nickel, lead, and cadmium, impair antioxidant defences, especially those involving thiol- containing antioxidants and enzymes (Stohs and Bagchi, 1995). A third important mechanism of free radical production is the Fenton reaction, by which ferrous iron (II) is oxidized by hydrogen peroxide to ferric iron (III), a hydroxyl radical, and a hydroxyl anion (Valko et al., 2005). The superoxide radical can reduce iron to its ferrous form. Copper, chromium, vanadium, titanium, cobalt, and their complexes can also be involved in the Fenton reaction (Lushchak, 2011). Activation of redox sensitive transcription factors such as AP-1, p53, and $\mathrm{NF}-\kappa \mathrm{B}$ is another mechanism by which metals can participate in producing oxidative stress. These transcription factors control the expression of protective genes which repair DNA and influence apoptosis, cell differentiation, and cell growth (Valko et al., 2005)

\section{Metals involved in oxidative stress in fish}

\section{Redox - active metals}

\section{Iron}

Iron is an essential element required for many physiological functions, and its homeostasis is strictly regulated by various mechanisms. In bio-logical systems iron exists in three oxidation states (II, III, and IV). The majority of iron in the organism is bound to haemoglobin, transferrin, ferritin, and ironcontaining enzymes. Therefore, only a trace amount of free iron is present (Valko et al., 2005). Excessive uptake of iron or disturbances in its regulation can be toxic which is related to its ability to catalyze ROS formation via the Fenton reaction. Elevated production of superoxide anions increases the release of free iron (Emerit et al., 2001). The deleterious effects of iron include DNA damage, lipid peroxidation (LPO), and oxidation of proteins (Valko et al., 2005). Lipid peroxidation and alterations in antioxidant enzyme activity in embryonic and adult medaka Oryzias latipes exposed to nanoiron was reported by $\mathrm{Li}$ et al., (2009). According to Baker et al., (1997), an ironenriched diet in the African catfish Clarias gariepinus induced LPO in the liver and heart. Significant increases in SOD activity and higher levels of LPO were observed in erythrocytes of cichlid fish from a metalcontaminated river, with the highest levels in 
spring, when the concentration of iron in water was elevated (Ruas et al., 2008).

\section{Copper}

Copper plays an essential function in a variety of metabolic processes. It is a component of many enzymatic and structural proteins, including $\mathrm{Cu}-\mathrm{Zn}$ SOD, cytochrome oxidase, and ceruloplasmin. Copper occurs naturally in soil and water. Mining, industrial discharges, and copper-based pesticides, especially algaecides, are sources of water contamination (WHO, 1998). Copper toxicity to fish and its bioavailability in water vary with physicochemical properties of water, i.e., $\mathrm{pH}$, alkalinity, suspended solids, organic compound content, and hardness (Di Giulio and Meyer, 2008). The concentration of free copper, cupric ion (II), increases with water acidity. Copper hydroxide predominates in water of pH 8.0 and higher (Tao et al., 2001). Calcium, as a contributor of water hardness, was shown to reduce the harmful effects of copper on the growth of Nile tilapia (AbdelTawwab et al., 2007). The cellular toxicity of copper can be explained through its participation in the Fenton reaction. Gravato et al., (2006) observed an increase in copper associated LPO and DNA damage in the European eel Anguilla anguilla pre -exposed to $\beta$-naphthoflavone (BNF). This study suggests a synergistic relationship be-tween copper and BNF Copper binds thiolcontaining molecules such as glutathione. The inhibition of total GSH was observed in the livers of three-spined sticklebacks Gasterosteus aculeatus exposed to copper sulphate. Concurrent with the depletion of GSH, enzymatic biomarkers such as CAT, SOD, and GPx increased within the first week of exposure and then recovered, concomitant with copper accumulation in the liver. The recovery of GSH and a return of antioxidant enzymes to basal levels suggest that metallothioneins play a role in detoxification
(Sanchez et al., 2005). Gravato et al., (2006) attribute the de-pletion of GSH to direct copper interference with GSH synthesis, inhibition of glutathione reductase, and the participation of GSH as a substrate in detoxification reactions. The depletion of GSH in fish muscle after copper sulphate exposure has also been reported (Jena et al., 2009).

\section{Redox - inactive metals and metalloids}

\section{Cadmium}

Cadmium is a non-essential metal with no known biological function. The source of cadmium in the aquatic environment is industrial activity (Stohs and Bagchi, 1995). Cadmium does not generate ROS directly, but can alter GSH levels and influence cell thiol status, inducing the expression of metallothioneins in the liver. Changes in GSH and MTs can lead to LPO of the cell membrane. Cadmium enters the electron transport chain in mitochondria, leading to accumulation of unstable semiubiquinones which donate electrons and create superoxide radicals. Cadmium also affects antioxidant enzymes, especially SOD and CAT, and is able to displace copper and iron in various proteins, freeing these metals to then participate in the Fenton reaction (Ercal et al., 2001). This decreased activity was explained by the authors as the direct binding of cadmium to CAT. Metallothioneins play a major role in the detoxification of cadmium, and this process is clearly organ-specific (De Smet et al., 2001). The induction of de novo synthesis of MTs following cadmium exposure has been described in several studies (Jebali et al., 2006; Ghedira et al., 2010). According to De Smet et al., (2001), MT induction following intraperitoneal injection of cadmium, as described by Ghedira et al., (2010), is evidence of a genetic ability to synthesise MTs. Contradictory results were reported from a field study conducted by 
Kovarova et al., (2009), where no significant correlation between cadmium liver content and MT concentration was observed. The effects of cadmium exposure on GSH levels vary with fish species, duration of exposure, and the chemical involved. Both increases and decreases in GSH have been observed, depending on field and experimental conditions (Kovarova et al., 2009; Cao et al., 2010; Jia et al., 2011).

\section{Mercury}

Mercury is an important pollutant of water world-wide. A variety of human activities are connected with mercury pollution (silver and gold mining, coal combustion, dental amalgams) (Luoma and Rainbow, 2008b). Organic methylmercury and inorganic (mercurous, mercuric) forms exist in nature. Organic forms are the result of methylation of inorganic mercury by microorganisms in sediments and water. Methylmercury is generally more toxic to fish than the inorganic forms (Houserova et al., 2006). Mercury reacts with the thiol groups of GSH, which can induce GSH depletion and oxidative stress in tissue (Stohs and Bagchi, 1995). Monteiro et al., (2010) described changes in biomarkers of oxidative stress following exposure to inorganic mercury. Methylmercury was shown to induce oxidative stress in several field studies (Larose et al., 2008; Mieiro et al., 2010). The data presented in these studies suggest that both organic and inorganic forms of mercury participate in the formation of ROS. Metallothioneins also play a protective role in response to mercury exposure. The mRNA expres-sion of two MT genes was noted by Navarro et al., (2009) in the liver of feral carp Cyprinus carpio from a mercury contaminated river. No biochemical evidence of oxidative damage associated with these changes was found in the tissue. This suggests that quantitative analysis of the mRNA expression of MT genes can be a suitable biomarker of subtoxic metal exposure in cases of elevated levels of metals and no evidence of oxidative damage in fish tissue.

The authors have observed increases in GSH levels following mercury exposure (Rana et al., 1995; Elia et al., 2000). Depletion of GSH was reported by Elia et al., (2003) and Mieiro et al., (2010). Metal-induced decreases in GSH levels could be the result of direct binding of the metal to GSH through its $\mathrm{SH}$ group (formation of metal-SG complexes) or of enhanced oxidation of this thiol (Elia et al., 2003). Collectively, these data suggest that GSH has a key role in oxidative-induced toxicity caused by mercury.

Fig.1 Oxidative stress

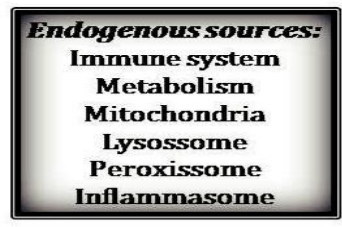

Oxidative Stress
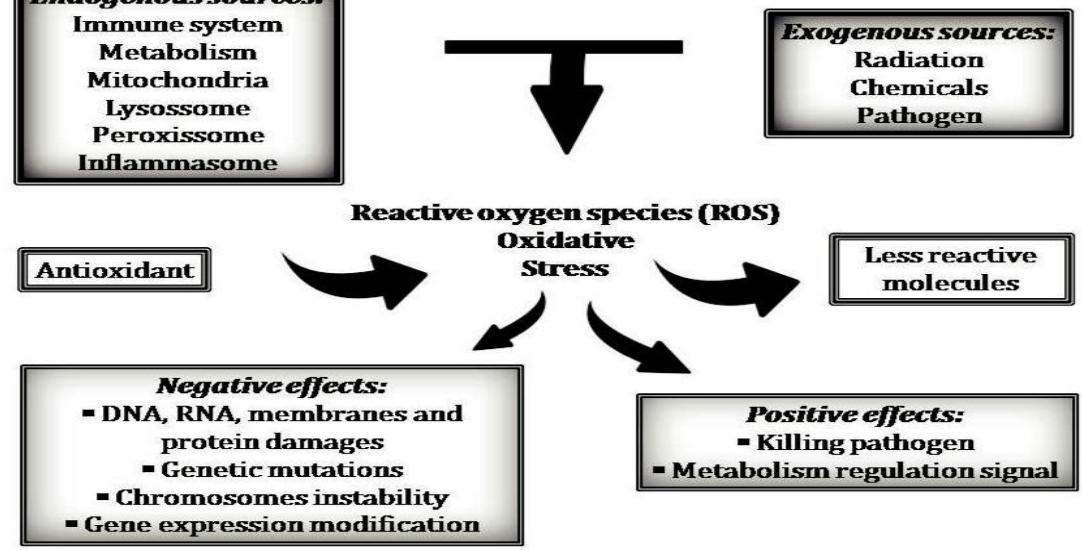


\section{Lead}

Lead is a major environmental pollutant. Paint, cosmetics, human medicines, food supplements, and petroleum-based fuels are sources of lead pollution (Stohs and Bagchi, 1995).Lead accumulation in sediment is of significance for aquatic organisms. Lead is not a transition metal and cannot readily undergo valence changes. Lead can induce oxidative damage through direct effects on the cell membrane, interactions between lead and haemoglobin, which increase the autooxidation of haemoglobin, auto-oxidized $\delta$ aminolevulinic acid, interactions with GR, or through the formation of complexes with selenium, which decrease GPx ac-tivity (Ercal et al., 2001). An intraperitoneal injection of lead was administered to the toadfish Halobatrachus didactylus and its effects on aminolevulenic acid dehydratase (ALA-D) activity, MT levels, and LPO in the liver, kidney, and blood were investigated over seven days (Campana et al., 2003). The results showed an in-crease in MT levels, suggesting that lead can induce the synthesis of MTs, although to a lesser degree than some other metals. The authors proposed that lead is not a good inducer of LPO, because a decrease in MDA levels was measured in the liver, and the induction of LPO observed in the kidney was ambiguous. No significant variations in ALA-D as a result of lead exposure were reported. Maiti et al., (2010) described elevated MDA levels in the brains of walking catfish Clarias batrachus following a 60-day exposure to waterborne lead. These results suggest that the manner and duration of exposure are important factors in lead-induced oxidative stress.

\section{Arsenic}

Arsenic is a known carcinogen in human. Arsenic forms inorganic and organic complexes in the environment. Arsenite (III) and arsenate (V) are inorganic forms that can be methylated. The trivalent arsenite is biologically more active than pentavalent arsenate. Glutathione plays a key role in the cell redox status induced by arsenic. Glutathione is an electron donor in the reduction of arsenate to arsenite. Arsenic cell metabolism generates ROS, although the mechanisms are not clear. Reactive nitrogen species are also involved in oxidative damage associated with arsenic (Bhattacharya and Bhattacharya, 2007). The central role of GSH in arsenic toxicity was described in several studies. The induction of LPO, an increased GSSG/GSH ratio, and excess production of hydrogen peroxide were observed in the Indian catfish Clarias batra-chus exposed to nonlethal doses of arsenic for 10 days (Bhattacharya and Bhattacharya, 2007). The authors explained the elevated concentration of hydrogen peroxide as arsenic-induced alterations of peroxisome. Oxidative stressinduced apoptosis was suggested by Seok $e t$ al., (2007) as a possible mechanism of arsenic toxicity in a zebrafish Danio rerio liver cell line. Arsenobetaine and arsenocholine are non-toxic organic forms of arsenic present in fish. According to Ciardullo et al., (2010), the majority of total arsenic in fish tissue is present as arsenobetaine. This is similar to the conclusions of Harkabusova et al., (2009). The data presented suggest that an assessment of arsenic speciation needs to be included in studies dealing with arsenic pollution, especially in field conditions, taking into consideration the risk to humans of fish consumption.

\section{Selenium}

Selenium as an essential element plays a role in anti-oxidant defences and is a cofactor for GPx. Preventive effects of selenite on heavy metal-induced stress in rainbow trout Oncorhynchus mykiss were described by Ates et al., (2008). Selenium can be toxic to fish at 
high doses. A source of selenium is coal mining from Se-rich rocks; selenate is the main form of Se originated from industrial discharges and selenium accumulates to toxic levels in the aquatic environment. Plants transform selenate to selenite and organoselenide. Various mechanisms have been suggested for Se toxicity, one of which is the generation of ROS (Miller et al., 2007).

\section{Other metals}

Apart from the above mentioned metals and metalloids, other metals are also connected with oxi-dative stress (nickel, vanadium, and cobalt) (Stohs and Bagchi, 1995) and can be detected in aquatic environments (Kandemir et al., 2010). Tributyltin and aluminium are widespread pollutants. The induction of oxidative stress may also play some role in the mechanisms of their toxicity in fish, but more studies need to be performed to explore this possibility (Wang et al., 2006; GarciaMedina et al., 2010; Ternjej et al., 2010).

Oxidative stress is a very important issue considering the problem of the aquatic environment contamination with pesticides. The above mentioned studies document that oxidative stress induced by metals is an important issue in aquatic ecosystems. The response of fish to oxidative damage after acute and also chronic metal exposure is evident under laboratory conditions as well as in field studies. The components of antioxidant defences are diversely influenced by metals. Both increases and decreases in enzyme activities and also enhanced and reduced levels of non-enzymatic components have been described after metal exposure. Metallothioneins (MT) seem to be a suitable biomarker of metal exposure, especially under laboratory conditions. In field studies the applicability of MT content in fish tissues as a biomarker is questionable following chronic metal exposure. The experimental conditions in field studies vary with a season and weather, and the physicochemical properties of water play an important role in metal solubility. Organic substances in water influence the availability of metal to fish and reduce metal toxicity. Some metals are rapidly bound to organic substances and thus cannot be detected in water; however, they can later become accessible in fish food. It should be borne in mind that fish of differ-ent species, sex, size, and age are involved in field studies. Another factor that can influence a representative sampling is fish migration. Therefore, field studies should be designed in such a way as to take into account the complexities of the aquatic environment. Fish can be used as bioindicators of metals in the environment by studying the induction of oxidative stress; however, the specific forms of biomarkers and mechanisms of their action still need to be investigated.

\section{Acknowledgement}

The author would like to thank Dr. Renu singh (Biotechnologist) for manuscript improvement as a.

\section{References}

Abdel-Tawwab, M., Mousa, M.A.A., Ahmad, M.H. and Sakr, S.F.M. 2007. The use of calcium pre -exposure as a protective agent against environmental copper toxicity for juvenile Nile tilapia, Oreochromis niloticus (L.). Aquaculture. 264, 236-246.

Ahmad, I., Hamid, T., Fatima, M., Chand, H.S., Jain, S.K., Athar, M. and Raisuddin, S. 2000. Induction of hepatic antioxi-dants in freshwater catfish (Channa punctatus Bloch) is a biomarker of paper mill effluent exposure. Biochimica et Biophysica Acta. 1523, 37-48.

Ahmad, I., Maria, V.L., Oliveira, M., 
Pacheco, M. and Santos, M.A. 2006. Oxidative stress and genotoxic effects in gill and kidney of Anguilla anguilla L. exposed to chromium with or without pre-exposure to beta-naphtho-flavone. Mutation Research. 608, 16-28.

Albuquerque, D.M.N., Lopes, J.B., Ferraz, M.S., Ribeiro, M.N., Silva, S.R.G., Costa, E.M.S., Lima, D.C.P., Ferreira, J.D.M., Gomes, P.E.B. and Lopes, J.C.O. 2017. Vitamin E and organic selenium for broilers from 22 to 42 days old: performance and carcass traits. ANAIS DA ACADEMIA BRASILEIRA DE CIENCIAS. 89, 1259-1268.

Ates, B., Orun, I., Talas, Z.S., Durmaz, G. and Yilmaz, I. 2008. Effects of sodium selenite on some biochemical and hematological parameters of rainbow trout (Oncorhynchus mykiss Walbaum, 1792) exposed to $\mathrm{Pb} 2+$ and $\mathrm{Cu} 2+$. Fish Physiology and Biochemistry. 34, 5359.

Babior, B.M., 1997. Superoxide: a two-edged sword. Brazilian Journal of Medical and Biological Research. 30, 141-155.

Bainy, A.C.D., 1996. Oxidative stress as biomarker of polluted aquatic sites. In: Val AL, Almeida-Val VMF and Randall DJ (Eds), Physiology and Biochemistry of the Fishes of the Amazon. INPA, Manaus, Brazil, Pp. 101-110.

Baker, R.T.M., Martin, P. and Davies, S.J. 1997. Ingestion of sub-lethal levels of iron sulphate by African catfish affects growth and tissue lipid peroxidation. Aquatic Toxicology. 40, 51-61.

Barreiros, A.L.B.S., David, J.M. and David, J.P. 2006. Estresse oxidativo: relação entre geração de espécies reativas e defesa do organismo. Quim Nova. 29, 113-123.

Bhattacharya, A. and Bhattacharya, S. 2007. Induction of oxidative stress by arsenic in Clarias batrachus: In-volvement of peroxisomes. Ecotoxicology and Environmental Safety. 66, 178-187.

Biller-Takahashi, J.D., Takahashi, L.S., Mingatto, F.E. and Urbinati, E.C. 2015. The immune system is limited by oxidative stress: dietary selenium promotes optimal antioxidative status and greatest immune defense in pacu Piaractus mesopotamicus. Fish Shellfish Immunol. 47, 360-367.

Brand, M. 2010. The sites and topology of mitochondrial superoxide production. Experimental Gerontology. 45, 466472.

Buettner, G.R., 1993. The pecking order of free radicals and antioxidants: Lipid peroxidation, -tocopherol, and ascorbate. Archive of Biochemistry and Biophysics. 300, 535-543.

Buonocore, G., Perrone, S. and Tataranno, M.L. 2010. Oxygen toxicity: chemistry and biology of reactive oxygen species. Seminars in Fetal and Neonatal Medicine. 15, 186-190.

Campana, O., Sarasquete, C. and Blasco, J. 2003. Effect of lead on ALA-D activity, metallothionein levels, and lipid peroxidation in blood, kidney, and liver of the toadfish Halobatrachus didactylus. Ecotoxicology and Environmental Safety 55,116-125.

Cao, L., Huang, W., Liu, J., Yin, X. and Dou, S. 2010. Accumulation and oxidative stress biomarkers in Japanese floun-der larvae and juveniles under chronic cadmium exposure. Comparative Biochemistry and Physiology C. 151, 386-392.

Chien, L.C., Yeh, C.Y., Huang, S.H., Shieh, M.J. and Han, B.C. 2003. Pharmacokinetic model of daily selenium intake from contaminated seafood in Taiwan. Science of the Total Environment. 311, 57-64.

Ciardullo, S., Aureli, F., Raggi, A. and Cubadda, F. 2010. Arsenic speciation in 
freshwater fish: Focus on extraction and mass balance. Talanta. 81, 213-221.

Cross, C.E., Halliwell, B., Borish, E.T., Pryor, W.A., Ames, B.N., Saul, R.L., Mccord, J.M. and Harman, D. 1987. Oxygen radicals and human disease. Annals of Internal Medicine. 107, 526-545.

De Smet, H., De Wachter, B., Lobinski, R. and Blust, B. 2001. Dynamics of $(\mathrm{Cd}$, $\mathrm{Zn}$ )-metallothioneins in gills, liver and kidney of common carp Cyprinus carpio during cadmium exposure. Aquatic Toxicology. 52, 269-281.

Di Giulio, R.T. and Meyer, J.N. 2008. Reactive oxygen species and oxidative stress. In: Di Giulio RT, Hinton DE (eds.): The Toxicology of Fishes. CRC Press, Taylor and Francis Group. 273324.

Dong, M., Liang, Y., Ramalingam, R., Tang, S.W., Shen, W.Y.E.R., Gopalakrishnan. S., Au, D.W.T. and Lam, Y.W. 2017. Proteomic characterization of the interactions between fish serum proteins and waterborne bacteria reveals the suppression of antioxidative defense as a serum-mediated antimicrobial mechanism. Fish Shellfish Immunol 62: 96-106.

Doyotte, A., Cossu, C., Jacquin, M.C., Babut, M. and Vasseur, P. 1997. Antioxidant enzymes, glutathione and lipid peroxidation as relevant biomarkers or experimental or field exposure in the gills and the digestive gland of the freshwater bivalve Unio tumidus. Aquatic Toxicology. 39, 93-110.

Elia, A.C., Dorr, A.J.M., Mantilacci, L., Taticchi, M.I. and Galarini, R. 2000. Effects of mercury on glutathione and glutathione-dependent enzymes in catfish (Ictalurus melas R.). In: Markert B, Friese K (eds.): Trace Elements Their Distribution and Effects in the Environment: Trace Metals in the Environment. Elsevier Science.
Amsterdam. 41-421.

Elia, A.C., Galarini, R., Taticchi, M.I., Dorr, A.J.M. and Mantilacci, L. 2003. Antioxidant responses and bioaccumulation in Ictalurus melas under mercury exposure. Ecotoxicology and Environmental Safety. 55, 162-167.

Emerit, J., Beaumont, C. and Trivin, F. 2001. Iron metabolism, free radicals, and oxidative injury. Biomedicine and Pharmacotherapy 55. 333-339.

Ercal, N., Gurer-Orhan, H. and Aykin-Burns, N. 2001. Toxic metals and oxidative stress part I: Mechanisms involved in metal induced oxidative damage. Current Topics in Medicinal Chemistry. 1, 529-539.

Finkel, T., 2011. Signal transduction by reactive oxygen species. Journal of Cell Biology. 194, 7-15.

Franco, R. and Martínez-Pinilla, E. 2017. Chemical rules on the assessment of antioxidant potential in food and food additives aimed at reducing oxidative stress and neurodegeneration. Food Chemistry. 235, 318-323.

Garcia-Medina, S., Razo-Estrada, A.C., Gomez -Olivan, L.M., Amaya- Chavez, A., Madrigal-Bujaidar, E. and GalarMartinez, M. 2010. Aluminiuminduced oxidative stress in lymphocytes of common carp (Cyprinus carpio). Fish Physiology and Biochemistry. 36, 875882.

Gaté, L., Paul, J., Nguyen, B.A.C., Tew, K.D. and Tapiero, H. 1999. Oxidative stress induced in pathologies: the role of antioxidants. Biomedical Pharmacy. 53, 169-180.

Ghedira, J., Jebali, J., Bouraoui, Z., Banni, M., Guerbej, H. and Bousetta H. 2010. Metallothionein and metal levels in liver, gills and kidney of Sparus aurata exposed to sublethal doses of cadmium and copper. Fish Physiology and Biochemistry 36, 101-107. 
Gravato, C., Teles, M., Oliveira, M. and Santos, M.A. 2006. Oxidative stress, liver biotransformation and genotoxic effects induced by copper in Anguilla anguilla L. - the influence of preexposure to $\beta$-naphthoflavone. Chemosphere. 65, 1821-1830.

Guardiola, F.A., Gónzalez-Párraga, P., Meseguer, J., Cuesta, A. and Esteban, M.A. 2014. Modulatory effects of deltamethrin-exposure on the immune status, metabolism and oxidative stress in gilthead seabream (Sparus aurata L.). Fish Shellfish Immunol. 36, 120129.

Halliwell, B., 2000. The antioxidant paradox. The Lancet 355: 1179-1187.

Halliwell, B., 2009. The wanderings of a free radical. Free Radical Biology and Medicine. 46, 531-542.

Halliwell, B., Aeschbach, R., Loliger, J. and Arouma, O.I. 1995. The Characterization of Antioxidants. Food Chemistry and Toxicology. 33, 601612.

Hamanaka, R.B. and Chandel, N.S. 2010. Mitochondrial reactive oxygen species regulate cellular signaling and dictate biological outcomes. Trends in Biochemical Science. 35, 505-513.

Harkabusova, V., Macharackova, B., Celechovska, O. and Vitou-lova, E. 2009. Determination of arsenic in the rainbow trout muscle and rice samples. Czech Journal of Food Sciences. 27, S404-S406.

Houserova, P., Kuban, V., Spurny, P., Habarta, P. 2006. De-termination of total mercury and mercury species in fish and aquatic ecosystems of Moravian rivers. Veterinarni Medicina. $51,101-110$.

Hsu, P.C. and Guo, Y.L. 2002. Antioxidant nutrients and lead toxicity. Toxicology. 180: 33-44.

Husain, S.R., Cillard, J. and Cillard, P. 1987.
Hydroxyl radical scavenging activity of flavonoids. Phytochemistry. 26, 24892497.

Jebali, J., Banni, M., Guerbej, H., Almeida, E.A., Bannaoui, A. and Boussetta, H. 2006. Effects of malathion and cadmium on acetylcholine esterase activity and metallothionein levels in the fish Seriola dumerilli. Fish Physiology and Biochemistry. 32, 9398.

Jena, S.D., Behera, M., Dandapat, J. and Mohanty N. 2009. Non-enzymatic antioxidant status and modulation of lipid peroxidation in the muscles of Labeo rohita by sub-lethal exposure of CuSO4. Veterinary Research Communications. 33, 421-429.

Jezierska, B. and Witeska M. 2001. Summary of metal-in-duced disturbances in fish organism. In: Metal Toxicity to Fish. Wydawnictvo Akademii Podlaskej, Siedlce. 214-243.

Jia, X., Zhang, H. and Liu X. 2011. Low levels of cadmium exposure induce DNA damage and oxidative stress in the liver of Oujiang colored common carp Cyprinus carpio var. color. Fish Physiology and Biochemistry. 37, 97103.

Kamunde, C., Clayton, C. and Wood CM. 2002. Waterborne vs. dietary copper uptake in rainbow trout and the effects of previous waterborne copper exposure. American Journal of Physiology-Regulatory, Integrative and Comparative Physiology. 283, R69R78.

Kandemir, S., Dogru, M.I., Orun, I., Dogru, A., Altas, L., Er-dogan, K., Orun, G. and Polat, N. 2010. Determination of heavy metal levels, oxidative status, biochemical and hematological parameters in Cyprinus carpio L., 1785 from Bafra (Samsun) fish lakes. Journal of Animal and Veterinary Advances. 9, 
617-622.

Kelly, S.A., Havrilla, C.H.M., Brady, T.C., Abramo, K.H. and Levin, E.D. 1998. Oxidative stress in toxicology: Established mammalian and emerging piscine model systems. Environmental Health Perspectives. 106, 375-384.

Kiley, P.J. and Storz, G. 2004. Exploiting thiol modifications. PLoS Biology. 2, 391-400.

Kovarova, J., Celechovska, O., Kizek, R., Adam, V., Harustia-kova, D. and Svobodova Z. 2009. Effect of metals, with special attention of $\mathrm{Cd}$, content of the Svitava and Svratka rivers on levels of thiol compounds in fish liver and their use as biochemical markers. Neuroendocrinology Letters. 30, 16769.

Lambeth, J.D. 2004. NOX enzymes and the biology of reactive oxygen. Nature Review Immunology. 4, 181-189.

Larose, C., Canuel, R., Luccote, M. and Di Giulio, R. 2008. Toxicological effects of methyl mercury on walleye (Sander vitreus) and perch (Perca flavescens) from lakes of the boreal forest. Comparative Biochemistry and Physiology. 147, 139-149.

Li, H., Jiang, W., Liu, Y., Jiang, J., Zhang, Y., Wu, P., Zhao, J., Duan, X., Zhou, X. and Feng, L. 2016. The metabolites of glutamine prevent hydroxyl radicalinduced apoptosis through inhibiting mitochondria and calcium ion involved pathways in fish erythrocytes. Free Radical Biology and Medicine. 92, 126140.

Livingstone, D.R. 2003. Oxidative stress in aquatic organ-ism in relation to pollution and agriculture. Revue de Medecine Veterinaire. 154, 427-430.

Livingstone, D.R. 2003. Oxidative stress in aquatic organ-ism in relation to pollution and agriculture. Revue de Medecine Veterinaire. 154, 427-430.
Luoma, S.N. and Rainbow, P.S. 2008a Sources and cycles of trace matals. In: Metal Contamination in Aquatic Environments: Science and Lateral Management. Cam-bridge University Press, Cambridge. 47-66.

Luoma, S.N. and Rainbow, P.S. 2008b. Methyl mercury. In: Metal Contamination in Aquatic Environments: Science and Lateral Management. Cambridge University Press, Cambridge. 368-392.

Lushchak, V.I. 2011. Environmentally induced oxidative stress in aquatic animals. Aquatic Toxicology. 1, 13-30.

Maiti, A.K., Saha, N.K. and Paul, G. 2010. Effect of lead on oxidative stress, $\mathrm{Na}+\mathrm{K}+\mathrm{ATPase}$ activity and mitochondrial electron transport chain activity of the brain of Clarias batrachus L. Bulletin of Environmental Con-tamination and Toxicology. 84, 672-676.

Malhotra, J.D. and Kaufman, R.J. 2007. Endoplasmic reticulum stress and oxidative stress: a vicious cycle or double-edged sword? Antioxid Redox Signal. 9, 2277-2293.

Mattos, B.O., Nascimento, Filho. E.C.T., Santos, A.A., Barreto, K.A., SánchezVázquez, F.J. and Shaw, A.C., Joshi, S., Greenwood, H., Panda, A. and Lord, J.M. 2010. Aging of the innate immune system. Curr Opin Immunol. 22, 507513.

Mieiro, C.L., Ahmad, I., Pereira, M.E., Duarte, A.C. and Pacheco, M. 2010. Antioxidant system breakdown in brain of feral gulden grey mullet (Liza aurata) as an effect of mercury exposure. Ecotoxicology 19, 10341045.

Miller, L.L., Wang, F., Palace, W.P and Hontela, A. 2007. Effects of acute and subchronic exposures to waterborne selenite on the physiological stress 
response and oxidative stress indicators in juvenile rainbow trout. Aquatic Toxicology. 83, 263-271.

Monteiro, D.A., Rantin, F.T. and Kalinin, A.L. 2010. Inorganic mercury exposure: toxicological effects, oxidative stress biomarkers and bioaccumulation in the tropical freshwater fish matrinxa, Brycon amazonicus (Spix and Agassiz, 1829). Ecotoxicology. 19, 105-123.

Moura, F.R., Brentegani, K.R., Gemelli, A., Sinhorin, A.P. and Sinhorin, V.D.G. 2017. Oxidative stress in the hybrid fish Jundiara (Leiarius marmoratus $\mathrm{x}$ Pseudoplatystoma reticulatum) exposed to Roundup Original. Chemosphere. $185,445-451$.

Navarro, A., Quiros, L., Casado, M., Faria, M., Carrasco, L., Benejam, L., Benito, J., Diez, S., Raldua, D., Barata, C., Bayona, J.M. and Pina, B. 2009. Physiological responses to mercury in feral carp populations inhabiting the low Ebro River (NE Spain), a historically contaminated site. Aquatic Toxicology. 93, 150-157.

Nishida, Y. 2011. The chemical process of oxidative stress by copper (II) and iron (III) ions in several neu-rodegenerative disorders. Monatshefte fur Chemie.142, 375-384.

Oost, R., Beyer, J. and Vermeulen, N.P.E. 2003. Fish bioaccumulation and biomarkers in environmental risk assessment: a review. Environ Toxicol Pharmacol. 13, 137-149.

Pietta, P. 2000. Flavonoids as Antioxidants. Journal of Natural product. 63(7): 10351042.

Rana, S.V.S., Singh, R. and Verma S. 1995. Mercury -induced lipid peroxidation in the liver, kidney, brain and gills of a fresh water fish Channa punctatus. Japanese Journal of Ichthyology. 42, 255-259.

Ruas, C.B.G., Carvalho, C.D., Araujo, H.S.S.,
Espindola, E.L.G. and Fernandes, M.N. 2008. Oxidative stress biomarkers of exposure in the blood of cichlid species from a metal-contaminated river. Ecotoxicology and Environmental Safety. 71, 86-93.

Sanchez, W., Palluel, O., Meunier, L., Coquery, M., Porcher, J.M. and AïtAïssa S. 2005. Copper-induced oxidative stress in three-spined stickleback: relationship with hepatic metal levels. Environmental Toxicology and Pharmacology. 19, 177-183.

Scandalios, JG. 2005. Oxidative stress: molecular perception and transduction of signals triggering antioxidant gene defenses. Brazilian Journal of Medical and Biological Research. 38, 995-1014.

Schieber M and Chandel NS. 2014. ROS Function in Redox Signaling and Review. Oxidative Stress. Current Biology. 24, 453-462.

Seok, S.H., Baek, M.W., Lee, H.Y., Kim, D.J., Na, Y.R., Noh, K.J., Park, S.H., Lee, H.K., Lee, B.H., Ryu, D.Y. and Park, J.H. 2007. Arsenite -induced apoptosis is prevented by antioxidants in zebrafish liver cell line. Toxicology in Vitro. 21, 870-877.

Sies, H. 1986. Biochemistry of oxidative stress. Angew Chem Int Ed Engl. 25, 1058-1071.

Sorg, O. 2004. Oxidative stress: a theoretical model or a biological reality. Comptes Rendus Biologies. 327, 649-662.

Stohs, S.J. and Bagchi, D. 1995. Oxidative mechanisms in the toxicity of metals ions. Free Radical Biology and Medicine. 2, 321-336.

Storey, K.B. 1996. Oxidative stress: animal adaptations in nature. Brazilian Journal of Medical and Biological Research. 29, $1715-1733$.

Tao, S., Wen, Y., Long, A., Dawson, R., Cao, J. and $\mathrm{Xu}$, F. 2001. Simulation of acidbase condition and copper speciation in 
fish gill microenvironment. Computers and Chemistry. 25, 215-222.

Ternjej, I., Mihaljevic, Z., Stankovic, I., Kerovec, M., Sipos, L., Zeljezic, D. and Kopjar N. 2010. Estimation of DNA integrity in blood cells of eastern mosquito fish (Gambusia holbrooki) inhabiting an aluminium-polluted water environment: an alkaline comet assay study. Archives of Environmental Contamination and Toxicology. 59, 182-193.

Theriault, A., Chao, J.T., Wang, Q., Gapor, A. and Adeli, K. 1999. Tocotrienol: A review of its therapeutic potential. Clinical Biochemistry. 32, 309-319.

Underhill, D.M. and Ozinsky, A. 2002. Phagocytosis of microbes: complexity in action. Annual Review of Immunology. 20, 825-852.

Valko, M., Morris, H. and Cronin, M.T.D. 2005. Metals, toxicity and oxidative stress. Current Medicinal Chemistry.
12, 1161-1208.

Veal, E.A., Day, A.M. and Morgan, B.A. 2007. Hydrogen peroxide sensing and signaling. Molecular Cell. 26, 1-14.

Wang, C.H., Zhao, Y., Zheng, R., Ding, X., Wei, W., Zuo, Z. and Chen, Y. 2006. Effects of tributyltin, benzo[a]pyrene, and their mixture on antioxidant defense systems in Sebastiscus marmoratus. Ecotoxicology and Environ-mental Safety. 65, 381-387.

Winston, G.W. 1991. Oxidants and antioxidants in aquatic animals. Comp Biochem Physiol C 100: 173-176.

Wood, Z.A., Poole, L.B. and Karplus, P.A. 2003. Peroxiredoxin evolution and the regulation of hydrogen peroxide signaling. Science. 300, 650-653.

Zamocky, M., Furtmuller, P.G. and Obinger, C. 2008. Evolution of catalases from bacteria to humans. Antioxid Redox Signal. 10, 1527-1547.

\section{How to cite this article:}

Babita Rani and Renu Singh. 2019. A Review on Metals Induced Oxidative Stress in Fish. Int.J.Curr.Microbiol.App.Sci. 8(07): 264-278. doi: https://doi.org/10.20546/ijcmas.2019.807.034 